\title{
Semiotics of Identity: Politics and Education
}

\author{
Tomasz Szkudlarek
}

Published online: 2 February 2011

(C) The Author(s) 2011. This article is published with open access at Springerlink.com

\begin{abstract}
In this text I concentrate on semiotic aspects of the theory of political identity in the work of Ernesto Laclau, and especially on the connection between metaphors, metonymies, catachreses and synecdoches. Those tropes are of ontological status, and therefore they are of key importance in understanding the discursive "production" of identity in political and educational practices. I use the conceptions of both Laclau and Eco to elucidate the operation of this structure, and illustrate it with an example of the emergence of the "Solidarność" movement in Poland, expanding its analysis provided by Laclau. I focus on the moment when one of particular demands assumes the representation of totality, which, in Laclau, is left to "circumstantial" determination. This moment inspires several questions and needs to be given special attention if Laclau's theory is to be used in theory of education. It is so because theory of education cannot remain on the level of the ontological (which is the core of Laclau's achievement), but has to theorize "nonontological" dimensions as well, that is the ontic (i.e. "content" of education), the deontic (duty, obligation, and the normative in general), as well as what I call the deontologicalthe very relation between "what there is" and "what there is not" (including that which should be) as the locus of education.
\end{abstract}

Keywords Identity · Politics · Education · Semiotics · "Solidarność" · Empty signifier

Contemporary theories of the political, and especially their conceptions of identity, propose important insights for educational theory. In this text I concentrate on semiotic aspects of Ernesto Laclau's theory of political identity, and especially on the connection between metaphors, metonymies, catachreses and synecdoches. In Laclau's work those tropes are of ontological status, which follows the tradition of psychoanalysis (in Freud and especially in Lacan, metaphor and metonymy form the "rhetoric machinery" of the

T. Szkudlarek $(\bowtie)$

Faculty of Social Sciences, Institute of Education, University of Gdańsk, Ul. Bażyńskiego 4, 80-952 Gdańsk, Poland

e-mail: pedts@univ.gda.pl 
unconscious). The "ontologization" of rhetoric is possible due to understanding discourse as the domain of the objectivity of the social.

My intention is to focus on the critical point in Laclau's theory, that is, the moment when one particular demand assumes the representation of totality. This involves a "radical (affective) investment" and, despite the strong theoretical apparatus of Laclau's conception, it remains a moment of discontinuity and is left to "circumstantial" determination (Laclau 2005, p. 95). If Laclau's theory is to be used in educational theory, this moment needs to be given particular attention. It speaks to the fundamental relation between universality and particularity and between the ontological and the ontic. Educational theory cannot solely focus on the level of the ontological (which is the core of Laclau's achievement) alone, but has also to theorize "non-ontological" dimensions, that is the ontic (i.e. "contents" of education), the deontic (duty, and the normative in general), as well as which I call the deontological-the very relation between "what there is" and "what there is not", including that which "could" and "should" be, as the locus of education.

In the following sections of the paper I will, first, provide a summary of Laclau's theory of identity. Then, in order to make his argument more applicable to practices of identity construction (which, I assume, constitute the core of education), I will analyse the rhetoric of identification supplementing Laclau's theory with Umberto Eco's semantics of the metaphor. I will use here the example of the emergence of "Solidarność" in Poland in 1980, expanding the analysis proposed by Laclau (2005). This analysis is aimed at providing some insight into what signifiers can be used in educational practices of building personal and collective identities. In the final section of the paper I will point to the need of re-theorizing education as identity construction with the use of contemporary semiotic theories, like Laclau's and Eco's, in the context of the present reduction of education to effective instruction, which in fact hides its involvement in identity politics in which schools participate, but cannot control either its course or their own involvement in the process.

\section{Identity, Hegemony and Empty Signifiers}

In Laclau, society is a construction that does not stem from any pre-defined basis. What defines its structures is discourse, understood as the domain of relations that precede the meaning of particular elements. This is also how Laclau understands objectivity: as relations, or structures, that precede the particular. Discourse, then, gains ontological status here. Discourse is the "terrain" of the objectivity of the social (Laclau 2005, p. 68). ${ }^{1}$

Social identities are constructed as differential, that is, the existence of externality, or of "the Other" is fundamental to their establishment. This sounds like Hegelian dialectics, but Laclau understands it differently. Hegel's conception of difference is logical, which means that difference is presupposed in the identity of the same, and that is why it can be re-appropriated into its structure. Laclau's ontology is based on heterogeneity, or radical difference, which means that identity cannot be theorized in terms of logic. According to Laclau, Hegel's system is consistent at the expense of excluding the heterogeneous beyond its borders: Hegel's "peoples without history" do exist, but they are not involved in the

\footnotetext{
1 In the reconstruction of Laclau's theory I am mainly referring to his On populist reason (Laclau 2005), although his theoretical argument has developed gradually since the 1980s (see e.g. Laclau and Mouffe 1985; Laclau 1990, 1996).
} 
logic. The same applies to Marx's exclusion of lumpenproletariat from class dialectics. Otherness, in both those cases, falls back into the same in a dialectic process because it works within structures cleansed of the heterogeneous. The Other in Laclau is positioned differently. For otherness to play its constitutive role, it cannot be "logically opposed" to identity. It must be based on something that belongs to the domain demanding identification, but is excluded from the task. "The only possibility of having a true outside", says Laclau (2005, p. 70), "is not simply one more, neutral element but an excluded one, something that the totality expels from itself in order to constitute itself." In other words, real problems with the construction of social identity start beyond the borders of Hegel's and Marx's worlds, precisely where their dialectics do not reach: with those elements that must be excluded for the system to establish itself.

Exclusion begins the process of constructing objectivity. Against the excluded element, other social demands ${ }^{2}$ appear equivalent. Retaining their particular differences, they share a "common difference" against the excluded. Referring to one of the examples provided by Laclau, demands of freedom of press, higher wages, independence of trade unions or national sovereignty, while maintaining their specific character, became equivalent in the opposition against the communist regime in Poland in 1980. So conceived equivalence presents both a problem with, and a chance for totality. Exclusion and particularity of demands make common identity problematic, but, as far as those demands are similar in terms of what they exclude (they are all formulated against the communist party), there appears a possibility of a common (initially negative) identity. This means that the demands are ontologically split: while keeping their particularity, they share at the same time an aspect of the universal-that which makes them equivalent against the excluded. It is on the basis of that equivalence that totality (identity) is striven for.

This totality is an object which is both impossible and necessary. Impossible, because the tension between equivalence and difference is ultimately insurmountable; necessary, because without some kind of closure, however precarious it might be, there would be no signification and no identity (Laclau 2005, p. 70).

This ontologically impossible but politically necessary totality (Laclau 1990) must find its representation to be accomplished. But conceptual representation (or "definition") of such heterogeneous entity is impossible. It can only be achieved in a form that allows for the heterogeneous; that is, when one particular difference (one of many demands in the chain of equivalence) "assumes the representation of an incommensurable totality" (Laclau 2005, p. 70). This representation (particularity standing for totality) is called hegemony. Laclau adopts the term from Gramsci, but argues that its meaning is identical with that of object petit $a$ in Lacanian psychoanalysis (Laclau 2005; see also Fink 1995; Žižek 1989; Lacan 2006).

The possibility of hegemony rests on the operation of empty signifiers, that is, on representations without concrete referential meaning (what they represent is attempted totality, or the very equivalence of diverse demands). Notions like "democracy," "nation," or "solidarity," when used as brands of political identities, cannot have clear conceptual definitions. As such representations cannot have conceptual form, an identity has to depend on additional instances that make it plausible: on radical affective gestures through which the desire of totality is invested into a partial object that starts to represent it (Laclau refers

\footnotetext{
${ }^{2}$ In Laclau, demand is the minimal unit of social ontology. Groups are formed through articulation of demands, like the subject is subject of desire in Lacan.
} 
to the notion of cathexis in Freud ${ }^{3}$; Laclau 2005, p. 71). Such affective mobilization, in turn, demands that particular rhetorical devices have to be engaged. The key role in this process is played by catachresis, described by Laclau as meeting "the need to express something that the literal term would simply not transmit" (Laclau 2005, p. 71). ${ }^{4}$ As the task of creating totality can only be performed by particularity assuming the position of the universal, synecdoche (pars pro toto, a part representing the whole) is another rhetorical figure with a strong ontological function.

However, the relation between the particular and the universal is not simply that of representation. Particular demands (in case of social identities) or desires (on an individual level) cannot form identity by a mere "leap" to universality that grasps the plethora of particulars in one conceptual framework. The universal can never be established in such a way, and that impossibility grounds in the very nature of the medium of the universal, that is language. This trope has a significant articulation in Lacanian psychoanalysis. Lacan rewrites Freudian theory, claiming that it is the very structure of language (the Symbolic order) that "produces" the unconscious. As language is always "the language of the Other", it can never grasp the totality of our experience (which Lacan calls the Imaginary), and there is always a difference between those two orders that elapses representation, and that constitutes what Lacan calls "the Real". ${ }^{5}$ In a way it is a residuum, a peculiar "leftover" of our conceptual efforts (the Symbolic) being incapable of grasping the texture of our experience (the Imaginary); something that "is there" and whose work we experience indirectly, but whose nature cannot be conceptualized. At the same time, as Žižek argues, "The Lacanian Real is the gap which separates the Particular from the Universal, the gap that prevents us from completing the gesture of universalization" (Žižek 1994, p. 43). It is the Real (the "insurmountable" tension between equivalence and particularity in Laclau), then, that constitutes the impossible dimension of identity. At the same time, "being there," it calls for being represented. As it cannot be represented conceptually, it is in this gap between particularity and universality, and between impossibility and necessity of representation, that hegemony-operating through the use of empty signifiers-has to "do the job" of identity construction. Empty signifiers, with their catachretic (heterogeneous) structure, match, or couple "from above" (at the level of signifiers) that which is symmetrically empty, unnameable "below," at the level of the Real that escapes representation. In this sense the empty signifier represents both the equivalence of particular demands, and the ontological impossibility of them being represented in totality: the very difference between the impossible and the necessary.

Let us return to how catachresis is understood by Laclau. I will first note that in older texts Laclau (e.g. 1990) tends to speak of metaphor, while in more recent ones he usually speaks, in a similar context, of catachresis. In many respects, and regardless of all inconsistencies in defining the term which we find in literature, we may say that catachresis is a kind of metaphor. Both tropes share the feature of heterogeneity: they are figures composed of "different" elements. However, metaphor (in its narrow sense) is sometimes thought of as ontologically "unnecessary", as a "finery of language" that may or may not

\footnotetext{
${ }^{3}$ In fact, in the USA editions of Freud. Originally Freud used the term Besetzung, which is semantically close to investment.

${ }^{4}$ Let us note that catachresis bears features otherwise also ascribed to metaphor. I will write more on this later.

5 This is one of the notions that make reading Lacan notoriously misleading. On the one hand, it refers to a "natural condition" of a "total", unreflected being of the infant that is lost since we start using the language, and on the other, as that condition is never accessible to our consciousness, the Real, against common connotations, stands in the position of "the unconscious".
} 
be used to transmit meaning. Catachresis, on its part, cannot be replaced by another term, and this feature is strongly stressed by Laclau. Its referent cannot find a singular representation-like in the notoriously repeated examples of "the neck of the bottle" or "a leg of the table." It is not merely about an "insufficiency of words", but about an ontological impossibility and the necessity of naming things that are "essentially unnameable" (Laclau 2005 , p. 71). Identity cannot be expressed otherwise than catachretically because it is always ontologically incomplete; it cannot be expressed by any single term.

In classical rhetoric, a figural term which cannot be substituted by a literal one, was called a catachresis. [...] If the empty signifier arises from the need to name an object which is both impossible and necessary, [...] the hegemonic operation will be catachrestical through and through (Ibid., pp. 71-72).

Catachresis is, then, the key to understanding identity as hegemony. Not only do we have to bridge the insurmountable heterogeneity here, but the very process of hegemonization is, in a way, discontinuous; it implies an indeterminate, radical investment of the meaning of the whole into one of the particularities. In a result, it is not possible to predict which signifier will perform the totalizing function on the basis of its "content", or reference. To quote Laclau,

"[...] if an equivalential link is going to be established [...], some kind of a common denominator has to be found which embodies the totality of the series. Since the common denominator has to come from the series itself, it can only be an individual demand which, for a set of circumstantial reasons, acquires a certain centrality (Ibid., p. 95, italics added).

This aspect of Laclau's theory has become one of its contested features. However, rather than rejecting this part of Laclau's thesis (as Žižek did in Žižek 2008, ${ }^{6}$ and in Butler et al. 2000), I will remain within this theory and try to make it "pedagogically applicable" within its logic. As this issue is crucial in theorizing education, the statement that the "choice" of a signifier that will embody identity depends on "circumstantial reasons" cannot be left as it is unless we fail in our attempts to find criteria on which such acts of hegemony depend.

\section{Metonymy, Metaphor, Catachresis, Synecdoche: The Process}

Educational theory, since its early years in the academe, has been very attentive to the relation between "form" and "content", to name just one dimension of the ontological/ ontic structure. It also included numerous instances of what "there is not" (potentialities, duties, values, etc.). I will try to analyse the semiotic dimension of this relation, usingalong with Laclau-0Umberto Eco's (1997) semantic theory of metaphor which, being in many respects similar to Laclau's semiotics, presents a synthetic account on some relations we need to investigate.

Eco connects metonymy, metaphor and catachresis (here understood in a narrower sense than in Laclau) into a transitive structure within what he calls the Global Semantic System. In his attempt to explain metaphor in purely semantic terms (without looking for similarities between its elements at the level of referents), Eco argues that metaphor is

\footnotetext{
6 Žižek defends the Marxist tradition of centrality of economy in defining social structures, re-articulated in Lacanian terms; hence his opposition to the notion of "any" signifier being capable of defining identity of the social.
} 
substantially connected to metonymy, and that the possibility of metaphorization and linguistic creativity in general, including the possibility of changing codes of culture, resides within language. Metaphor in Eco is understood similarly to how Laclau understands catachresis. Its function is ontological: it provides for possibilities of creating new cultural codes.

The problem of the creativity of language emerges [...] each time that language-in order to designate something that culture has not yet assimilated [...]—-must invent combinatory possibilities or semantic couplings not anticipated by the code. Metaphor, in this sense, appears as a new semantic coupling not preceded by any stipulation of the code (but which generates a new stipulation of the code) (Eco 1997, p. 252).

Catachresis, in turn, is in Eco something like a "late" (or "dead") metaphor, a metaphor that has lost its creative novelty and started to work as "part of the code", as a culturally established collocation-a feature of "closure" also acknowledged by Laclau.

The metaphor, once it has become usual, enters as part of the code and in the long run can fix itself in a catachresis ('the neck of the bottle', 'the leg of the table'). The fact remains, however, that the substitution took place because of the existence, in the code, of connections and therefore contiguities. This would lead us to state that the metaphor rests on a metonymy (Eco 1997, p. 262).

The sequence of metonymy, metaphor and catachresis reflects the same order, and their relations are based on very similar structural rules as those described by Laclau in the move from equivalence (which, rhetorically, is metonymy) to identity. ${ }^{7}$ What Eco brings into this structure is a slightly different description of the internal logic of transition from equivalence (metonymy) to metaphor and catachresis. According to Eco, metaphor (and hence, also catachresis) is formed as a leap in the chain of metonymies, by a "short circuit of a pre-established path" (ibid., p. 263). That path is formed by metonymic contiguities that in Eco can occur on the level of signifiers or signifieds. ${ }^{8}$ Laclau is more radical here. In his conception there seems to be no ground for codified "pre-established paths" of contiguities, although we can see chains of equivalence as precariously playing this role; in this respect, any articulation of demands is ontologically possible. With all necessary restrictions and reservations, however, we may generally say that Eco and Laclau share a similar view on how change comes to culture/society: through the invention of new terms that link heterogeneous elements related by metonymic contiguity. Eco's observation that metaphor is formed as a leap in the chain of metonymies (in a "horizontal" move within the chain of equivalence) is similar to Laclau's notion of articulation. ${ }^{9}$ Such translation (Laclau read through Eco and vice versa) suggests that it is already the very process of articulation that structures the metaphor which will compose identity; second, that those elements that may eventually be coupled in metaphor (or catachresis in Laclau) need to share "something" in the connotations of cultural code (pre-established in Eco, precarious

\footnotetext{
7 For an analysis of this semiotic structure in Laclau's theory see Wenman (2003).

${ }^{8}$ In some theories, contiguity can also occur in the non-semiotic sphere of materiality. Such articulation positions metonymy as "first order" semiosis, directly linked to non-linguistic realities; see, for example, Pelc (1967).

9 This issue is crucial for understanding how articulation can be understood pedagogically. See Ruitenberg (in press).
} 
in Laclau). The third element that appears in Eco is some "semiotic economy" of metaphorization; the fourth, an interesting idea how affect is involved in the semiotic process. We need to say more on the latter two issues now.

Metaphors in Eco can be "good" or "bad." A "good" or "inventive" metaphor can always be explained by filling the gap between its elements with mediating metonymies (like when explaining a joke to a slow thinker). This points to an internal economy in metaphor: the distance between its elements cannot be too small, because then the metaphor is banal and it does not "work" as a new, inspiring figure; it cannot be too large, either, because then the metaphor is not seen as metaphor at all; the elements seem unconnected and need "explication" that kills the effect. As Eco says, inventive metaphor works through excitation: its novelty and its productive force, revealing connections previously not perceived, create fascination and something we could call—after Laclau and Freud-infatuation, here understood as a desire to be involved in the sphere of "radiation" of the new articulation.

What Eco says of excitation as modus operandi of metaphor can explain the affective, energetic dimension of which Laclau speaks in his account on affective investment (cathexis) in terms of the very semiosis of identity formation. Even though for Eco the ground for theoretical analysis lies in literary practices (excitation may then be experienced by seduced readers), we may also think of it as working internally for the subject as creative illumination that reveals the so-far unconscious meaning of ourselves; as joy of self-articulation, of moving from the potential (the contiguous but mentally disconnected, mute, residing "in the code") to the actual (verbalized, given a name, mythically unified as "self"). Coming back to Laclau's analysis of political identities, we can see that if hegemony is based on metonymy/metaphor/catachresis, not only does it force people to subordinate, but it also attracts them through excitation, and this process can be explained by the very nature of rhetorical devices applied in the process of identity construction. Many times Laclau acknowledges this rhetorical significance of affect, but Eco's idea of excitation achieved through the "short circuit" of signification seems to give it a more tangible dimension. Then follows the transformation of metaphor into catachresis: "When finally, metaphors are transformed into knowledge, they will at last have completed their cycle: they become catachreses" (Eco 1997, p. 269). Excitation typical of the early stages of identity formation is replaced by a relatively stable hegemonic representation in which heterogeneity "dies" as fixed collocation. The catachresis of empty signifier in those "mature" states of identification is, then, a late, or used up metaphor emptied of its affective potential which elevated it to the hegemonic position, placing it at the same time in the position of a synecdoche.

Such conceptualization suggests that the formation of catachresis, which assumes the role of hegemonic identification, may follow the economy of "inventive" metaphors; and that it is the very nature of metaphorization that brings affect into the process. So described semiotic conditions of hegemony should help us tackle the issue of what signifiers are capable of "doing the job" of identity formation. Is there anything in the signifiers themselves that makes them attractive as potential signs of identity, as objects petit a into which the demand of identity can be invested? Remaining within the debate on the political, I will address this question analysing the case of the emergence of Solidarnosć in Poland in 1980.

\section{What Works? The case of 'Solidarność'}

In On Populist Reason, Laclau (2005, p. 81) says that "the Solidarność symbols [...] did not remain the particular demands of a group of workers in Gdańsk, but came to signify a 
Fig. 1 The semiotic construction of "Solidarność"

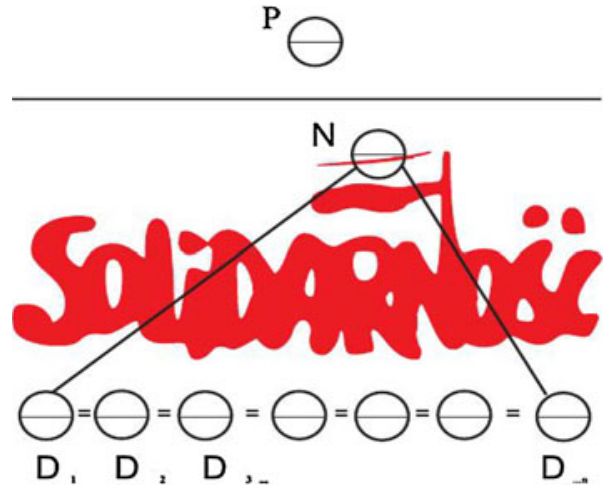

much wider popular camp against an oppressive regime". Let us describe this moment in more detail. The 1980 Gdańsk strikes were supported by a number of opposition groups with diverse demands (one of which was the creation of independent trade unions), ranging from Christian through nationalist to socialist, all blaming the ruling Polish United Workers' Party (PZPR) for economic crisis and political oppression. The silent, and very rarely pronounced issue was the Soviet domination over the country. Protests in the shipyards started in defence of a laid off union activist, but then spread over the country in a wave of solidarity strikes. The strike committee in Gdańsk quickly expanded, incorporating representatives of other industrial centres in Poland, and became the chief partner for negotiations with the government that covered a broad agenda of economic and political issues. The final agreement included consent to register a trade union that was a horizontal structure, cutting across trades and businesses (which is typical of populist movements rather than trade unions), and that union adopted the name of Solidarnos'́c (solidarity).

The word "solidarność" appeared in two contexts before the emergence of the new union. First, it was used by activists as a technical term describing the nature of proliferating strikes. In this meaning, as a call for endurance in industrial action, it appeared in graffiti. Second, it appeared in the shipyard and in the streets of Gdańsk in the soon famous poster designed by Jerzy Janiszewski, a few days before the end of strikes. It is important to notice that it was not a logo of the union then, as the union did not exist yet. This means that it could be the very design of the poster that made the union leaders adopt it as signifier of the new organization. The logo was immediately "recognized" by strikers as expressing their struggle and widely distributed in the shipyard and in the streets of the city. "People took this sign as if they had waited for it," Janiszewski says (quoted in Daszczyński 2005). When we look at it through the lens of Laclau's theory, we can see how the semiotic construction of the sign could have contributed to the success of the political movement. I consider this case to be an illustration of the hypothesis that not all signifiers can perform the function of representation in hegemonic identification equally well; that there must be "something" in their composition that makes them preferable tools of identification. In the figure below we can see the "Solidarność" logo imposed on a diagram composed of elements representing Laclau's theory of identity (Laclau 2005; Fig. 1).

The inscription in the poster looks like a demonstrating crowd. The "waving" letters, each of which is different, are physically adjacent. We have an image of "togetherness" of heterogeneous elements that can represent diverse demands raised during the strikes. ${ }^{10}$ In

${ }^{10}$ In the context of 1980 strikes the letters in the poster could also be read as different trades and factories "standing together" in industrial action. 
Laclau's (2005) diagrams, demands (D1 ... Dn) are represented by circles linked by equation marks that represent their equivalence. They are split, which means that the demands are of dual nature: each of them is particular (freedom of press, independent unions, better living conditions for workers, etcetera), but they all share an aspect of universality (their equivalence). As Laclau maintains, the equivalence of demands is achieved in relation to an excluded element that belongs to the social, but is refused its share in the creation of totality. What is excluded in this case is the United Polish Workers' Party (PZPR) represented by the "P" element behind the horizontal line above the logo. In the authoritarian socialism of that time, all large factories were owned by the state, the state was run by the Party, and therefore all acts of resistance (even in trivial cases) were aimed against that dual hegemony. That structure was very well represented in everyday language by the notion of "Them." The term was used as signifier of the anonymous nature of power, ${ }^{11}$ which means that also at the level of exclusion we should think of empty signifiers that are construed as split objects, both particular (here a concrete party with its Politburo, newspapers, etcetera) and universal (representing "naked power" permeating all social structures). The "Us" of equivalent social demands meets that abstract dimension of "Them" in power, whose concrete officers are but epiphenomenal representations incapable of independent action or responsibility. Identity is here construed in mutual relation of two universalities ("our" equivalence against "their" naked power).

On the second, positive level of identification, we have to mention two things. First, the letters are red, which is the colour appropriated by the Party and here recuperated by the workers' movement. Second, the demonstration is united under the national flag. One of the letters, or demands of the movement (the letter N) is "elevated" above other elements and provides them with a unifying signifier of the Nation. It is still positioned as particular (one among many demands), but it also gives shape to the new totality (the nation without the Communists). As I mentioned before, national sovereignty demands were rarely formulated overtly at the time of the strikes and were usually silenced as irresponsibly dangerous (they were feared to invite military confrontation with the USSR). In this context, the presence of the flag "demonstrates the unspeakable." Theoretically, it points to the importance of considering registers of articulation in the analysis of political identities. Things unsaid, unnameable, can otherwise be subject to iconic symbolization.

Another important issue is the retroactive work of totalizing signifiers. Laclau, along with the psychoanalytic tradition, claims that identity is in a way constructed "backwards," in a gesture that we could (after Deleuze and Guattari 2003) call "falling back" onto the surface of inscription of that which has been abstracted. In terms of Laclau's analysis of hegemony, it means that the national demand, tacitly represented by the flag, is elevated to the "dignity of the Thing," invested with power to represent the "impossible wholeness." Once positioned as such, it then works "back" onto the chain of equivalent demands (like those of higher wages or union rights) and redefines them as cases in the struggle for national sovereignty. However, there is another dimension of that retroactive work that is of importance for educational applications. Once the movement has been iconically signified "as national," its opponent (the Party) has been tacitly deprived of Polish nationality. Such identification made it easy to think of the Party as representing Soviet interests alien to the national ones.

\footnotetext{
11 Its meaning was significantly shifted by Teresa Torańska (1988), who used it as the title of her collected interviews with several top-rank officers of the Stalinist regime 1945-1956, giving "them" concrete names and faces.
} 
This analysis illustrates that, at least occasionally, there is "something" in the semiotic and aesthetic composition of the signifiers that makes them applicable in identity formation. The identity of the populus constructed in the course of the 1980 events in Poland could have taken different forms based on signifiers referring, for example, to class, religion, or justice. None of those possible identifications found a symbol equally powerful to that proposed by Janiszewski. In a way it proved "irresistible" in its aesthetic simplicity and rhetorical complexity. The logo works as a visual metaphor that links heterogeneous elements in an otherwise "unspeakable" manner. In one momentary perception we can see that we (workers) are the nation. The logo also brings together the notions of difference ("messy" letters...) and identity (...standing together, literally, in solidarity). It is almost a "total sign" (symbolic, iconic and indexing, pointing to a clearly recognizable event), in form that can be grasped in one glimpse of the eye. In fact, it presents an adequate visual theory of the movement. I think this condensation of tropes united in an aesthetic form made this sign exciting enough to "do the job" of retroactive unification of the political subject. Over time, the sign became a stable representation of the movement, losing its heterogeneity and exciting novelty. It became catachretic (in Eco's terms, as part of the code) and started to work in a quasi-conceptual manner ("metaphor turned to knowledge" Eco 1997, p. 269), defining solidarity as "workers standing together in the name of the nation." In such a closure, the semiotic identification shaped by the logo was not indifferent to the construction of antagonisms that followed the establishment of the union.

\section{Ontological, Ontic, Deontic, Deontological: Identity and Education}

In formal terms, Laclau's theory can be almost completely transferred to pedagogy and work as theory of identity building in education, and I will not use the remaining space of the paper for this transcription. Instead I will try to say why it is worth it.

Against the yet dominant jargons of education as a tool of economic growth, reducing its business to effective and measurable instruction, it still is an institutionalised practice of identity construction, both at individual and collective levels. However, the "new Symbolic order" that links its business to economy leaves people in education in a kind of fog as to the identity work; instead of being part of planned, rational activity of the school, it is being erased and disconnected from understanding other practices of identity formation, like commercial campaigns, TV news or political propaganda. This situation makes it difficult not only to include identity work in curriculum planning, but also to understand the whole array of tasks connected to identity building that are still performed by the school. I assume that one of the functions of schooling is the production of empty signifiers that are utilized in identity building industries, usually located outside the school. It is performed by means of cognitive practices in which certain terms are systematically detached from their experiential meaning in ritual repetitions, de-contextualized, abstracted and re-contextualized so that their meaning eventually becomes too complex and vague to be grasped. This process needs thorough empirical research, but we may venture a hypothesis that in the course of schooling, key categories in curricula (like "culture", "nation", "democracy", "science", etcetera) are circulated as important and at the same time impossible to define or understand, and that their incomprehensibility is systematically produced. Schools are factories of empty signifiers and of subjects who are ready to use them in their quest for identity. However, seldom do they consider this to be part of their planned curricular activity. In nineteenth- and twentieth-century pedagogies the situation was different and identity building — usually of national identity—was an overtly 
acclaimed task. The shift towards globalisation apparently dismantled that curricular activity; in fact, it redefined its goals in terms of economic universalism and turned its practice into hidden curricula. This brings a question if the school should and could intervene in this process: it is a question of political responsibility and pedagogical autonomy of schooling. It is also a question if Laclau's language of the rhetoric construction of identity is pertinent for the task of understanding more of what is happening at schools. My opinion is that it can point and give names to several domains so far overlooked in our understanding of schooling.

My intention in this respect is in fact similar to that of Laclau's in his attempt to see populism not it terms of what it lacks (like rationality or clear ideological stance), but what it is (a political logic of constructing the populus as the subject of democracy). We might repeat this gesture and ask the question of what positive effects the school produces by its "negative" means (like repetitiveness, boredom, incomprehensibility and the lack of connection to the external world). The present stress on a consumerist variety of individualism (school choice, student-centered pedagogies, etcetera) turns many of the typical operations of the school into obsolete, incomprehensible absurdities that are still there by some mistake or negligence. If we shift to the level of the ontological, we may look at those "lacks" as part of the political logic of schooling, not only in terms of how they serve particular ideological interest (which was the concern of hidden curriculum research), but how they construe the system as such. We should bear in mind that any process of ridicule, of making things incomprehensible or marginal, may be of political nature and may point to some unexpected importance of such things. To put it short, I want to propose that we pay more attention to those educational activities that can be understood in terms of production of empty signifiers, and that we trace those signifiers in the practices of identification outside the school, with constant attentiveness to the question whose identities and what identities are built with the use of the notions we manage to empty of any conceivable meaning in schools.

In the section about "Solidarność" I tried to suggest that there are some aesthetic, rhetorical and pedagogical qualities that are probably decisive of the applicability of signifiers in identity construction. If I were to conclude that line of my argument, I should say that there are some minimal conditions that probably have to be met by such signifiers, apart from their "emptiness." The first is that they have to bridge demands that are part of the same cultural code or experiential domain, in other words, that are metonymically linkable. In practice it implies that "cultural codes" are themselves pedagogically produced in systematic teaching and can, therefore, be pedagogically changed with metaphoric devices. Second, those metaphors/catachreses should be innovative; their novelty is the condition of excitation, and may be the most effective road to successful affective investment.

Those "technicalities" may be of importance if we decide to do more than use Laclau's theory in an analytical way, if we want to return to pedagogies of conscious identity construction in schooling, reclaiming responsibility for this process and the right to propose and strive for political projects in education. This would mean a return to a utopian understanding of pedagogy as partly autonomous, as capable not only of "making people," but also of "making worlds."

That, however, poses a series of other questions I also tried to address in the paper.

In Laclau, the structure of identity is ontologically open, and this openness is the very condition of the political, of the indeterminate and only precariously definable character of the social; but its ontic content makes a difference in terms of political consequences. Exactly the same pertains to the pedagogical. It is not enough to take care of the formal 
qualities of signifiers, structures of connections and creative methodologies of teaching. The content also matters. It is not indifferent if empty signifiers used in the process evoke, through possible metonymic contiguities, fascist, liberal or socialist connotations. Laclau is very clear that the ontological by itself "is not enough" to explain the process. "Since society as fullness has no proper meaning beyond the ontic contents that embody it, those contents are, for the subjects attached to them, all there is" (Laclau 2005, p. 226). Still, the outstanding quality of Laclau's theory does not help much in understanding such choices. If identity is ontologically impossible and politically necessary, it seems that-somehow conversely to practical expectations - we can be fairly precise in theorizing the impossible (ontological) dimension, while we have to remain vague in declarations of the importance of "right choices" and responsibilities in the domain of the politically necessary. Indirectly, this illustrates what we can understand by radical investment in social thought. Whatever we decide in the domain of the political is not ontologically determined; we have to take responsibility for such decisions. Exactly the same pertains to education. If we are politically and pedagogically responsible for our investments, we should make them consciously. How do we distinguish between "good" and "bad" empty signifiers? Can we judge or evaluate them?

From Eco we can imply that "good", or felicitous signifiers are those following the internal economy of metaphor. But that is a purely technical "goodness." We need ethical criteria here, and they can be of a pragmatic nature. Empty signifiers should be tested against their consequences. We can use various signifiers as cathectic devices that bring "impossible unity" to our heterogeneous demands/desires, but, as we know, any identity is differential, that is, it must relate to exclusion and difference. If we cannot imagine "the varieties of the good" particular signifiers can create (or indeed, if they all create the same good-identity), we should perhaps judge such chances against the negative criterion, probably more accessible to our rationality: who do we exclude on the way to unity? (Szkudlarek 1993) And how we construe them? Even if we are aware that somebody must be excluded from totality in the making, the "who" question introduces the unavoidable (and tragic, impossible to be satisfied) ethical dimension into the operation of hegemony: it breaks its neutral, ontological mechanics with a touch of human otherness, it gives the excluded the face. Why do we exclude them? We are speaking of an impossible and necessary ethics of exclusion here, provoked, for instance, by Torańska's book.

In this brief pedagogical reading of Laclau we have moved from the ontological (the universal, structure, metaphor, catachresis, synecdoche) through the return of the ontic (the particular, content, metonymy, connotation), to the necessity of the deontic (ethics, obligation, responsibility). As I said, educational theory and practice must be open to the issues of contents and particularity. We have to know the semantics of possible identities and build them as articulations within particular cultural codes, always within their contexts. And we cannot escape responsibility for such constructions and for exclusions they call for. Elaboration of this structure needs more space and has to be taken elsewhere, but we may initially point to two consequences of such interrogation. One, the most radical, is a temptation that we reject the notion of identity as a guiding concept in education: any exclusion, when confronted with awareness of the "who" of the other, is unethical, it cannot be justified by the mere desire of identity; hence we might think of education against identity (Szkudlarek 1993). However ethical it is, this argument only leaves the work of identity and exclusion to be done by others, often with no ethical responsibilities. Another consequence - this time "radical" in the meaning that speaks to more conservative connotations (as turning to "roots") - is the observation that we may have to revive the traditional discourse of values as that which can suggest conceptual tools for the 
purpose of "judging emptiness," regardless of idealistic connotations that contrast with Laclau's project. Let us recall that within the Kantian Sein and Sollen dichotomy, values in philosophy of education are defined as those that "do not exist" but "oblige" (Nawroczyński 1947). We may transpose that old concept into Laclau's theory and see values as empty signifiers that "do not exist" but "call" us to identity. The tradition of axiology is rich in classifications and analyses that might be informative in our understanding of what signifiers can work as hegemonic devices, how they can do so, and what can be possible consequences of their work. However, the very notion of value and the whole discourse of axiology need critical reinterpretation for such a purpose. Its aim should be understanding education in its mediating ontology of occurring in between "what there is" and forms of the nonexistent (like the becoming, the (im)possible or the duty). We could call this political dimension of education, calling us to responsibility for the way we deal with things to come, with the ontological relation to the nonexistent, the deontological.

Acknowledgments I express my gratitude to Komisja Krajowa NSZZ "Solidarnośc” in Poland for their permission to use the logo of "Solidarność", and to the Lower Silesia University Publishers in Wrocław for the permission to use the elements of Laclau's diagram, in Fig. 1 included in the paper. I also want to thank the anonymous reviewer and the editor of this special issue, Claudia Ruitenberg, for their comments that helped me to make the paper more coherent.

Open Access This article is distributed under the terms of the Creative Commons Attribution Noncommercial License which permits any noncommercial use, distribution, and reproduction in any medium, provided the original author(s) and source are credited.

\section{References}

Butler, J., Laclau, E., \& Žižek, S. (2000). Contingency, hegemony, universality. Contemporary dialogues on the left. London and New York: Verso.

Daszczyński, R. (2005). Logo "Solidarności” [The logo of Solidarność]. Gazeta Wyborcza. Available online http://wyborcza.pl/1,93886,2883008.html. Accessed 29 March 2010.

Deleuze, G., \& Guattari, F. (2003). Anti-oedipus: Capitalism and schizophrenia. Minneapolis: University of Minnesota Press.

Eco, U. (1997). The semantics of metaphor. In R. E. Innis (Ed.), Semiotics: An introductory anthology (pp. 250-271). Bloomington: Indiana University Press.

Fink, B. (1995). The Lacanian subject: Between language and jouissance. Princeton, NJ: Princeton University Press.

Lacan, J. (2006). Ecrits: A selection. London and New York: Routledge.

Laclau, E. (1990). New reflections on the revolution of our time. London: Verso.

Laclau, E. (1996). Emancipation(s). London: Verso.

Laclau, E. (2005). On populist reason. London: Verso.

Laclau, E., \& Mouffe, Ch. (1985). Hegemony and socialist strategy. London: Verso.

Nawroczyński, B. (1947). Życie duchowe : zarys filozofii kultury [Spiritual life: An outline of the philosophy of culture]. Kraków, Warszawa: Księgarnia Wydawnicza F. Pieczątkowski i ska.

Pelc, J. (1967). Zastosowanie funkcji semantycznych do analizy pojęcia metafory [The application of semantic functions in the analysis of the concept of metaphor]. In H. Markiewicz (Ed.), Prolblemy teorii literatury [Problems of literary theory] (pp. 86-118). Wrocław: Ossolineum.

Ruitenberg, C. W. (in press). Learning to articulate: From ethical motivation to political demands. In G. Biesta (Ed.), Philosophy of education 2010. Urbana, IL: Philosophy of Education Society.

Szkudlarek, T. (1993). The problem of freedom in postmodern education. Westport, CT: Bergin \& Garvey. Torańska, T. (1988). Them: Stalin's Polish puppets. New York: Harper Collins.

Wenman, M. A. (2003). Laclau or Mouffe? Splitting the difference. Philosophy and Social Criticism, 29(5), 581-606.

Žižek, S. (1989). The sublime object of ideology. London: Verso.

Žižek, S. (1994). Identity and its vicissitudes: Hegel's 'Logic of Essence' as theory of ideology. In E. Laclau (Ed.), The making of political identities (pp. 40-75). London: Verso.

Žižek, S. (2008). In defence of lost causes. London: Verso. 